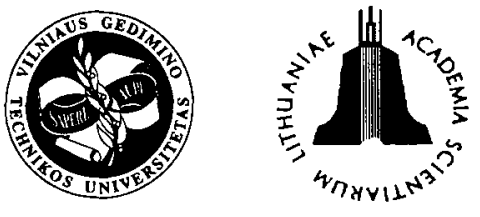

JOURNAL OF CIVIL ENGINEERIING AND MANAGEMENT

http:/www.vtu.It/cnglish/cditions

2003, Vol IX, No I, 68-75

\title{
EXPERIMENTAL INVESTIGATIONS IN CHISELLING SOLID CONCRETE
}

\author{
Friedel Peldschus ${ }^{1}$, Jens-Thorsten Wild ${ }^{2}$ \\ 'Leipzig University of Applied Science, 132 Karl Liebknecht St., D-04277 Leipzig, Germany. \\ E-mail: peldschu@fbb.htwk-leipzig.de \\ 2 fera-Bau Leipzig, Lampestr. 9, D-04107 Leipzig, Germany. E-mail: wild@fera-bau.de
}

Received 17 Sept 2002; accepted 09 Jan 2003

\begin{abstract}
Experimental research was performed for analysing the chiselling process. The conditions of crack formation and crack propagation have been analysed. In the first step impact tests with a standard chisel shapes and with a pointed chisel were performed. These tests represented the basic investigations into the chisel load effects on mechanical processing of concrete. In the next step precise modifications were applied to the flat-chisel cutting edge with the aim of improving the cutting-edge geometry.
\end{abstract}

Keywords: concrete, chiselling process, fracture mechanics, crack propagation, impact loading, drop device.

\section{Introduction}

In the redevelopment of buildings, solid concrete has to be mechanically processed. Powerful tools are needed when this kind of work is to be done to a great extent. For manufacturing these tools, experiences made under operating conditions have to be considered. Therefore the effects of the chisel loading are to be investigated in laboratories. The analysis of the results and scientific research up to the present [1] shall render an increase in productivity by the development of appropriate tools.

The present state of research on the aimed destruction of concrete using hand-guided drill hammers and chisel hammers is essentially well-proven concerning the interaction of the machine and the chiselling tool. An enormous improvement of these tools has been achieved in the past by a steady optimisation of the mechanical, electronic, pneumatic and control parts, eg by the electropneumatic principle (Doepper) [2, 3].

While the optimisation of the machine (drill and chisel hammer) including the tool(chisel)-machine (hammer) interface has reached a hardly improvable standard, the optimisation of the tool-concrete interface is still at an early stage of development. For this reason the authors try to improve the tool-concrete interface, which so far has only been investigated to a little extent.

This interface is the zone where the impact force of the machine, which is transmitted via the tool (chisel), is applied to the concrete body. The processes and effects involving the impact-loaded chisel cutting edge and the concrete structure below and surrounding it are investi- gated in order to achieve an improvement of concrete processing. This concerns the Meso range (two-phase model) or the micro range (poly-phase model).

Basically, two tendencies were found in the research literature. Investigations of the concrete in the Meso range or micro range were mainly performed under static loading. This involved experimental as well as analytical research, and comprehensive evaluations and analytical models have been worked out $[4,5]$.

Also investigations of dynamic loading of large concrete parts (slabs, columns and beams) due to motor vehicles, aircraft crashes or other impact loading were performed [6].

Investigations of the fracture and failure behaviour of concrete due to a fracture initialisation caused by dynamic forces, like the impact loading via a chisel, are very complicated and difficult to analyse theoretically. Up to the present time no scientific papers about the impact force application are known, in which the aim was to analyse the fracture initialisation and fracture development up to the total failure while the concrete is not considered in the engineering or structural range, ie not as a homogenous material. The research literature also included related areas, eg brittle materials (ceramics, rock) [7].

\section{Test set-up}

Due to the chosen form of the energy input with a dropping device it was possible to perform a precisely defined single impact. The kinetic energy for such an impact was transmitted by a drop body similar to the piston of a chisel hammer [8]. 


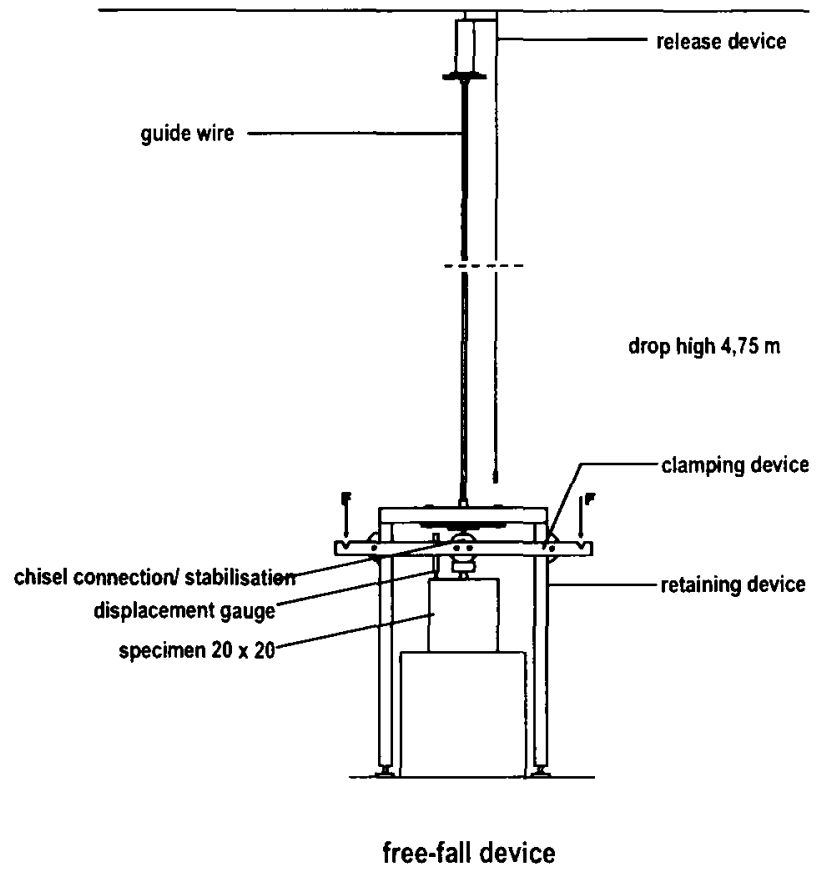

Fig 1. Schematic representation of the free-fall device

The amount of kinetic energy for a single impact could be precisely determined by a variation of the drop body mass. This amount was chosen in the range of the adequate amounts of kinetic energy of the drill hammers used in the subsequent experiments.

A device developed by the authors had to be built in the test laboratory of the Leipzig University of Applied Science in order to perform the necessary experiments. Fig 1 shows the schematic representation of it.

The test installation consists of an upper part, the release device, and a lower part, the retaining device. Both components are connected by adherence and positive engagement to a vertical I-beam, which is, in turn, integrated into the system of the hall. Three wires are mounted between the two parts. These guide wires are used only for the initial alignment of the drop bodies in order to reach a vertical position of their longitudinal axis. As the release position is vertically aligned with the central impact point, the drop body reaches a vertical position immediately after the release to the free fall. Due to this vertical position the drop body falls without any further friction and transfers its kinetic energy abruptly to the chisel, which stands still. The wires are made of patented cast-steel strings for music instruments by the company 'Stahl- und Drahtwerke Roeslau' [9]. It is characteristic of them that they can be extremely tightened. Therefore they immediately compensate any deflection of the drop body's longitudinal axis from the vertical position, which might occur after the release. In this process the contact area of drop body and wires is negligible. The upper part of the test installation serves as a mounting for the wires as well as for the release.
The adjusting screws on the release device and on the retaining one allow a vertical alignment. The possible but rarely occurring change in the vertical alignment during a heavy use of the test installation can be compensated by adjusting screws. It was occasionally observed that the drop body moves out of the guide wires due to a deflection from the vertical position.

This possibility of moving out proves again that the wires are not supposed to be a guidance associated with frictional loss.

The retaining device consists of the following elements. The connection and stabilisation of the chisel is done by a clamping device. By this device the chisel was pressed to the test specimen with a total force of $400 \mathrm{~N}$. This corresponds to the manual pressure force measured in pre-tests with drill hammers and combination hammer in vertical position. Static forces, which can be varied, are applied. The clamping force is transmitted by a very narrow outer circular cone. The contact area is so small that its influence on the actual chisel body can be neglected.The displacement gauge for tracking the intrusion is retained by a device. The concrete test specimen is laid on a massive concrete base and it is, as a whole body, clamped firmly in three directions to its bottom side. Concrete bases with various heights are available in order to adapt the kinetic energy of the single impact to the various combination hammers to be compared.

Fig 2 shows the cylindrical drop bodies used in the drop tests. The impact surface of these bodies was rounded according to the ones used with the electro-pneumatic principle in the drill hammers (Doepper) [10]. This rounding made sure that the impetus was transmitted abruptly to the chisel. In this way an inclination of the impact bodies and thus a non-vertical force application could be prevented.

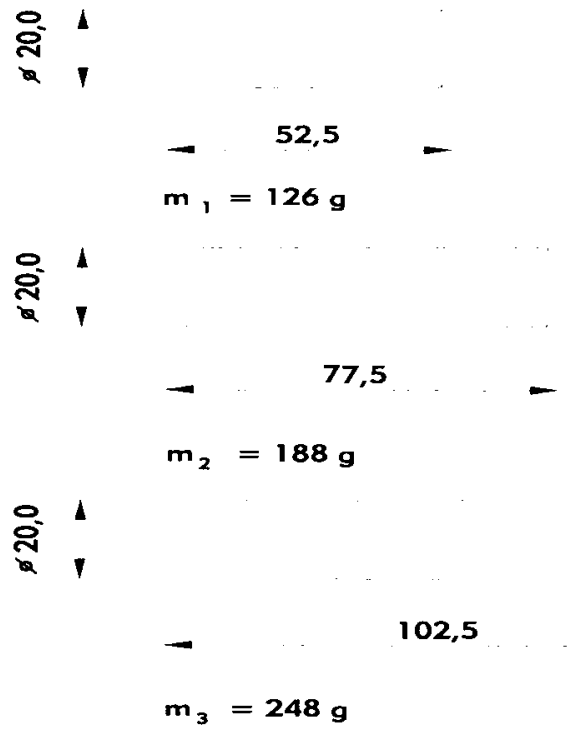

Fig 2. Dimensions and masses of the drop bodies used to generate different amounts of kinetic energy for a single impact 
The possibility of choosing the kinetic energy of the single impact is based on the differences between the various cylindrical drop bodies.

The drop bodies' masses were selected according to the kinetic energy of the single impacts of the drill hammers used in the real-life tests. The amount of energy for the smallest mass $m_{1}$ corresponds to the combination hammer TE 54. A variation of the kinetic energy amount was rendered by the height-adjustable mounting of the test specimen. The kinetic energy of the single impact for mass $m_{2}$ corresponds to the combination hammer TE 92.

Drop height of the mass $h=4,75 \mathrm{~m}$. The impacting velocity is calculated as follows:

$$
\begin{aligned}
& v=\sqrt{2 \cdot g \cdot h}, \\
& v=9,65 \mathrm{~m} / \mathrm{s}
\end{aligned}
$$

The kinetic energy of the single impact is

$$
W={ }_{2}^{m} \cdot v^{2}
$$

and correspondingly the numbers for the 3 masses [11]:

\begin{tabular}{|c|c|}
\hline $\begin{array}{c}\text { mass } \\
\mathrm{m} \text { in }[\mathrm{g}]\end{array}$ & $\begin{array}{c}\text { kinetic energy } \\
\mathrm{W} \text { in }[\mathrm{Nm}]\end{array}$ \\
\hline 126 & 5,87 \\
\hline 188 & 8,76 \\
\hline 248 & 11,55 \\
\hline
\end{tabular}

\section{Test specimens}

Cubical test specimens of concrete were made for the experiments with the drop device. They had the composition listed below and three different sizes: $10 \times 10 \mathrm{x}$ $10 \mathrm{~cm}, 15 \times 15 \times 15 \mathrm{~cm}$ and $20 \times 20 \times 20 \mathrm{~cm}$.

For the concrete of the strength class 35 , Portland cement of the quality grade PZ 35 , made by factory Zementhuette Coswig/Elbe, was used. The aggregates were composed according to the screening line B (largest grain $16 \mathrm{~mm}$ ).

Grain diameter moisture of aggregates:

$$
\begin{array}{lll}
0-2 \mathrm{~mm} & 44 \% & 3,0 \% \\
2-8 \mathrm{~mm} & 34 \% & 1,0 \% \\
8-16 \mathrm{~mm} & 22 \% & 1,5 \%
\end{array}
$$

The test specimens were made with a water/cement ratio $W / Z=0,47[12]$.

\section{Measuring method for tracking cracks}

The total amount of energy which was transmitted to the specimens up to the fracture was measured in all experiments as well as the total intrusion depth and the concrete mass which broke off.

Due to the precise single impact in the drop device the effect of every impact on the intrusion and the crack propagation could be recorded.
In the tests with the distance of $4,5 \mathrm{~cm}$ to the edge, the amount of energy transmitted to the specimen in terms of the crack formation and the crack propagation could be recorded.

In the test with a small distance between the chisel and the edge of the plate, only the total amount of energy transmitted to the specimen could be recorded due to predominantly short time until the crack formation.

In addition to measuring, the dimensions of the masses broken of the concrete were recorded for characterising the shape and the angle of the crack propagation.

While the amount of energy transmitted to the specimen (total amount and for a single impact) and the intrusion depth could be measured with a greater accuracy in the drop tests, certain restrictions had to be made for the tests with the chisel hammer.

The amount of kinetic energy was measured using an electronic chronometer. Reaction times of $* 1 / 10 \mathrm{~s}$ are to be assumed for the process of handling the chisel and observing the breaking off. However, due to the variance in the processing of the material concrete these reaction times have only a minor importance. In the drop tests the total intrusion depth was measured with the intrusions of the single impacts with an accuracy of $0,01 \mathrm{~mm}$.

In the tests with the drill hammer, only the total intrusion depth could be measured. This was done with an accuracy of $* 1 \mathrm{~mm}$.

The masses broken off were measured using a balance with an accuracy of $* 1 \mathrm{~g}$ for both drop tests and real-life chiselling tests.

The dimensions of the masses broken off were measured with an accuracy of $* 5 \mathrm{~mm}$.

To investigate the crack surface created during chiselling, a procedure was chosen and developed which recorded the desired steps of the crack propagation and allowed to see them after the final fracture. This desired crack tracking became feasible due to a colour-indication method.

The colours had to fulfil two important requirements:

on the one hand, it was necessary that they could spread up to the crack tip even at great depths;

- on the other hand, the subsequently applied colours should not interfere with each other.

Appropriate colours were developed in cooperation with a laboratory for organic systems, research and industry consultance in Leipzig/Luetzschena after an extensive testing.

The colours are based on two different solvents:

- the first solvent is water and

the second one is acetone.

A plural tenside decreasing the viscosity of the liquids, was added to the aqueous solutions [13]. It increases the creeping capability and facilitates the application of the colours with compressed air. Colours from the microscopy (colouring of tissue) were used and proved to work well. 
The problem of the influence of a subsequent colour on the colour applied before (mixing, flushing) was solved using a fixing substance. This is a polyacrylatecopolymer which cures insolubly after the oxidation, ie when the solution has dried, it cannot be washed out by subsequent colours.

For very deep cracks, eg with large specimens or at a great distance from the edge, colour solutions based on acetone were developed yet. These guaranteed to reach even the tip of very deep cracks due to the viscosity of acetone, which is the smallest possible one for liquids.

The percentages of the composition of the colour solutions are as follows:

$$
\begin{array}{ll}
2 \% \text { colour } & \\
\text { blue - (Krypurblau) } & * \text { Diazofarbstoff } \\
\text { red - (Eosinrot) } & * \text { Phenolphtalein } \\
\text { yellow - (Naphtolgelb) } & * \text { Diazofarbstoff } \\
\text { green - (Malachitgrün) } & * \text { Rosanilinfa } \\
20 \% \text { polyacrylate-copolymer } \\
78 \% \text { solvent (water, acetone) }
\end{array}
$$

Due to their improved pigment dissolving, the lighter colours yellow and green could reach the crack tip without difficulties, also when the air pressure decreased at greater depths. For this reason the solvent acetone was used for the lighter colours and because it also showed improved viscosity characteristics.

The colours were applied to the crack from the concrete surface by a prolonged needle. In addition to the decreased viscosity of the colour indicators, they were pushed into the furthest crack tip using compressed air. In pre-tests and also during the whole performance of the actual experiments, the limit of the crack width, up to which the colour indicators could spread, were determined as $10 \mathrm{~mm}$. This crack width still belongs to the micro-crack range, where the concrete can still transmit a considerable amount of its maximum stress [14]. After applying the colours along the crack front, hot air was pressed into the crack and the specimen was heated in the region of the subsequent breaking-off until the solvent evaporation. After the oxidation and the insoluble curing of the applied colour indicator the crack state is recorded corresponding to the amount of energy transmitted to the specimen up to this moment.

\section{Conclusions for a modified design of the cutting- edge geometry}

After testing the drop device and basic experiments with the chisel hammer, which served for investigating the concrete destruction in the chiselling process, the conclusions were made. An increase in performance can primarily be accomplished through an improved cuttingedge geometry of the flat chisel. The idea behind modifying the chisel design was to find a good ratio of the intrusion phase to the disruption phase. As a resuit of this, an increased processing performance should be ac- complished. In the first stage six modifications of the flat chisel form were investigated. In this way the influence of the geometry change on the processing performance could be determined.

One criterion was the lateral design of the cutting edge. It was assumed that a better crack forming could be accomplished by sharpening the lateral edge, because of the crack forming on both sides of the narrow chisel cutting edge. In addition it had been proved by experiments with the pointed chisel that due to the lateral pressure forces the crack is initialised at a certain distance from the chisel. The lateral sharpening of the cutting edge should, on the one hand, prevent the formation of a lateral compression area and, on the other hand, a stress concentration in the direction of the initial crack propagation. Both properties aim at leading the micro cracks, which have been formed by a destruction of the concrete's structure, as effectively as possible to a rational crack that grows to a fracture [15].

Another modification of the flat-chisel cutting edge was made in order to reduce the notch energy. A trapezoidal form was given to the chisel cutting edge for a decrease of the initial resistance at the beginning of the intrusion phase. A transmission of the necessary cleaving forces is not possible until a certain depth and thus contact surface, which depend on various influences (distance to edge, kinetic energy of the single impact). Up to this stage only destruction of the concrete body surface occurs (associated with the formation of splinters). Here it is possible that several layers break off subsequently. This behaviour can primarily be noticed with blunt impact bodies. A decrease in the amount of energy transmitted to the specimen before the creation of a solid contact by a reduction of the penetration effect was aimed through the reduction of the cross-section at the chisel edge. The total surface of force transmission was, however, decreased too in this way.

According to the tests with the pointed chisel an earlier crack initialisation was aimed by the force concentration under and beside the downsized chisel cutting edge. However, with an increasing intrusion depth the contact surface area increases and improves the transmission of the cleaving forces.

A third modification, which also resulted from the experiments with the crack tracking, was the setting back the central part of the cutting edge and the corresponding creation of two lateral teeth. Thus the contact surfaces between concrete and chisel were reduced too. In this way higher shock compression stresses should be applied through these stress concentration points. As a result, a better stress application at the points of the crack initialisation was aimed, and additionally a separation of the large compression area below the cutting edge into two smaller ones was intended. The breaking of the concrete below the cutting edge due to the separation of the stress concentrations was the aim of this modification. It should lead to a noticeable loosening up directly under 
the concrete surface and thus it should create a gap under the cutting edge, which gives a better point of application for the forces at the crack front. In this way a similar crack pattern should occur.

On the basis of these findings, six chisel modifications were analysed (Figs 3-5).

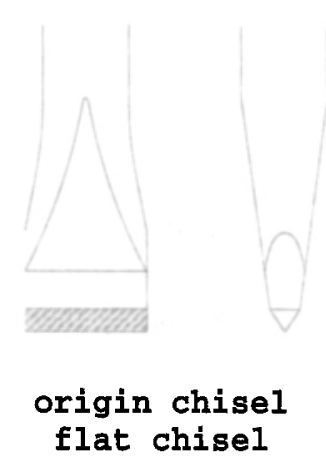

Fig 3. Origin chisel
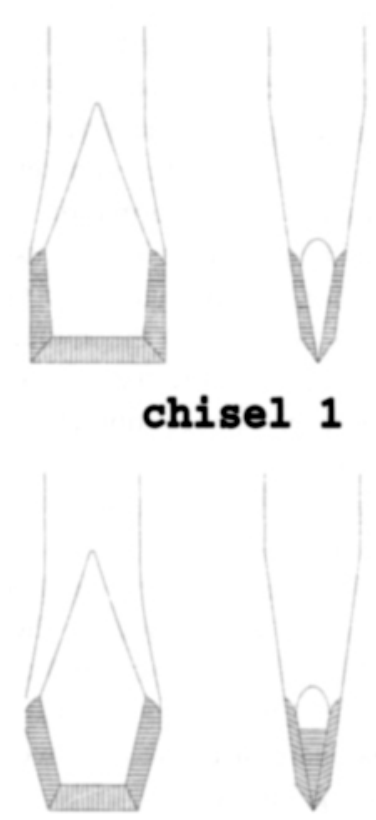

chisel 2

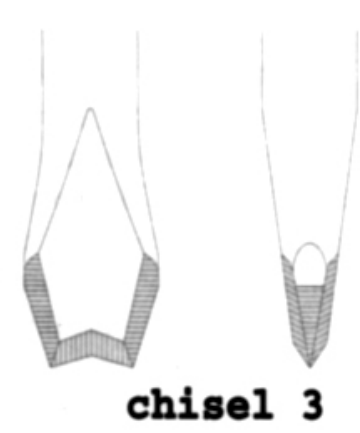

Fig 4. Chisel modifications 1-3

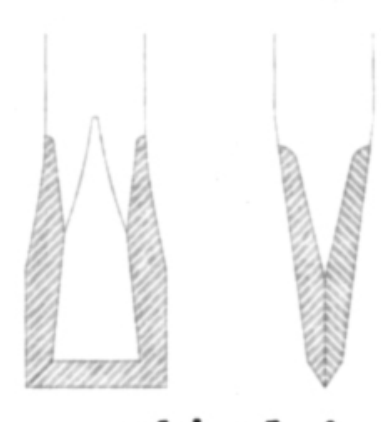

chisel 4

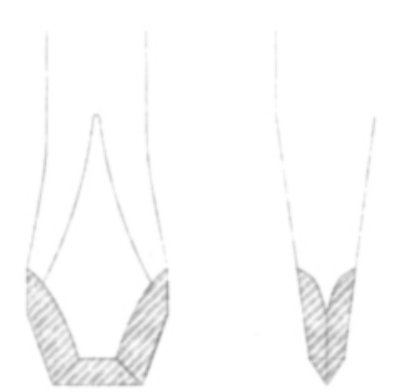

\section{chisel 5}

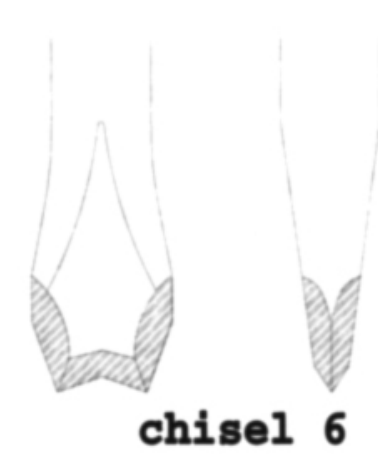

Fig 5. Chisel modifications 4-6

The investigations were performed for all chisel versions in the drop device as well as with the two chisel hammers TE 54 and TE 92. The aim was to compare the performance of the different types of chisels. A separation of the cutting-edge designs and existing dependencies on various parameters (eg intrusion ability) should be proofed by statistic significance checks and correlation analysis.

The experiments with the real-life chisel hammer were performed in two steps. In the first step the six chisel modifications mentioned above were analysed. In the second step the findings from these experiments were used to improve the processing performance and to prove the performance of the best chisels.

Three stages were distinguished in the analysis of the energy input at the intrusion of the different chisels into the concrete: the start intrusion stage, the crack stage and the pre-fracture stage. The calculated average values are shown in Fig 6. 


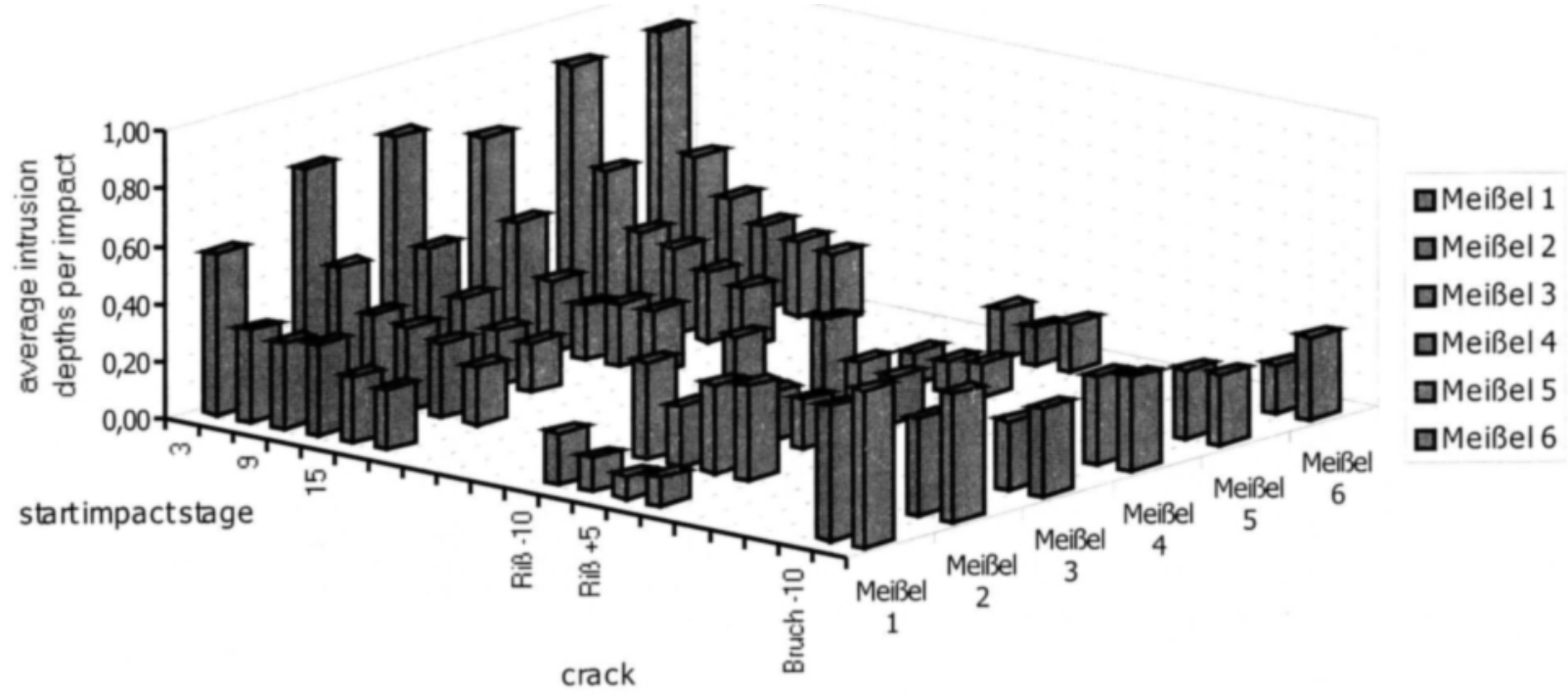

impacts

fracture stage

Fig 6. Representation of the average intrusion depths per impact of three different stages (Meißel-chisel, Riß-crack, Bruch-fracture)

The analysis of the intrusion depths increase shows distinctively that

- the chisel with a conical cutting edge makes greater intrusion depths at the start stage;

- the sharp cutting edge has a positive effect at least in the intrusion process;

- immediately before and during the formation of the microcrack(s) the intrusion depths decrease relatively strongly, while they remain constant or rise after;

- in comparison with other chisels, the highest intrusion depths occur immediately before the fracture with the chisel with the most impacts between crack and fracture (but also with the greatest contact surface).

The experiments of the chisel types 1-6 and of the standard chisel have shown that positive as well as negative effects are obtained with the modifications.

The important results are mainly the energy fractions and fracture stages, which occur during chiselling and contradict each other. The positive effect on the notch stage, which is obtained by an improvement of the intrusion ability, is not existent anymore in the subsequent cleaving stage, because it is caused by a reduction of the contact area. In contrast, an increased contact area has a positive effect on the cleaving stage. The relative energy losses through the edge resistance are reduced by a lateral force application area that is as large as possible.

These contrasting effects have to be compensated by a matching cutting-edge geometry. The contrasting tendencies of the chisel 2 and 3 to the chisels 5 and 6 are a clear notice for this. The intrusion behaviour was improved for both groups by the trapezoidal cutting-edge geometry. The differences are found in the lateral design of the cutting edges. While a lateral wedge form was left on chisels 2 and 3 , chisels 4 and 5 were grinded to a narrow lateral burr. Due to this sharp edge these chisel forms tend to perform like the pointed chisel, which had the lowest processing performance of all chisels in chiselling on the edge of a plate.

After the principal experiments with the chisel hammer in the context of the basic investigations of crack tracking and the various edge breaking-off tests, the chosen chisel modifications were examined and compared in extensive sets of experiments. Electro-pneumatic combination hammers by the company HILTI were used for these experiments.

The aim was to investigate the behaviour of the chisel variants in practice-oriented application in the mechanical processing of concrete.

\section{Results}

With the performed experimental investigations the experiences of the mechanical processing of concrete up to the present could be extended. The findings about the different chisel forms, which were made based on the energy amount transmitted to the specimen, render an improved design of tools. The results from the developed drop device (Fig 7) correspond well to the results from the real-life experiments (Fig 8). Thus it is possible under laboratory conditions to make a good assessment of the performance of new tools.

The questions on the effect of the amount of energy for a single impact on different cutting-edge geometries could be answered more distinctly. Furthermore the conditions of a strength increase of the concrete under the impact areas could be modified. The application of the 


\section{Energy specific mass}

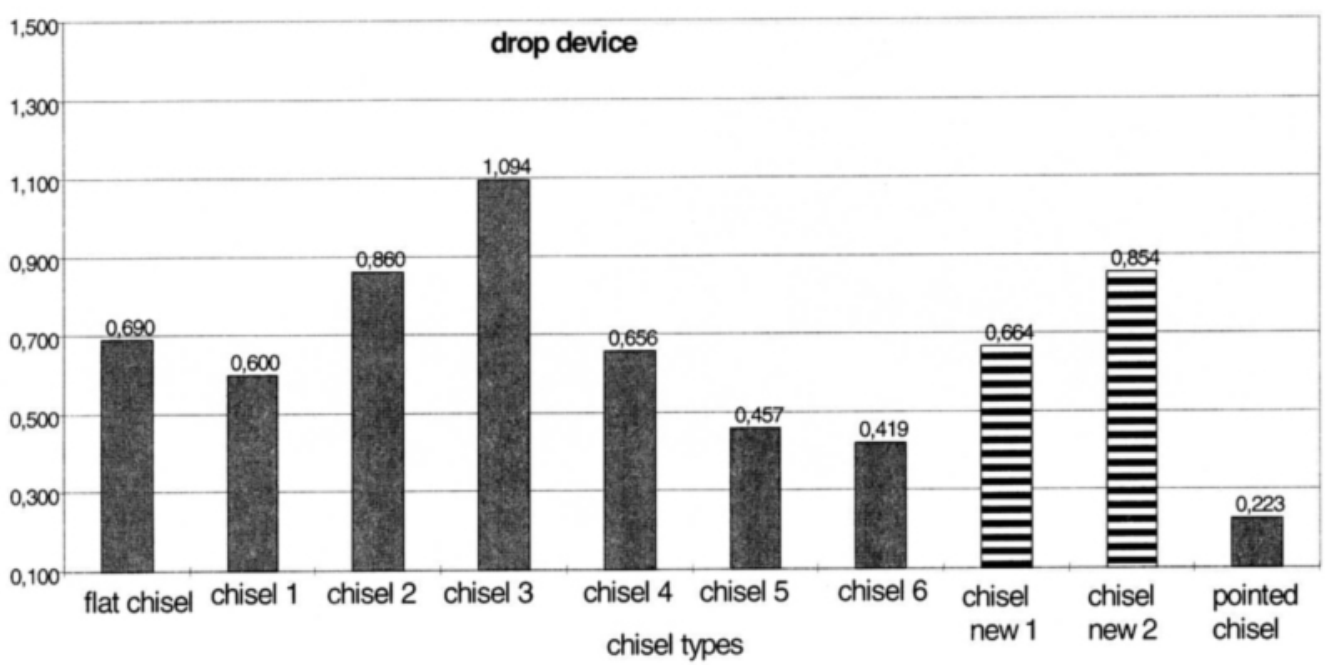

Fig 7. Results of the laboratory experiments

\section{Energy specific mass}

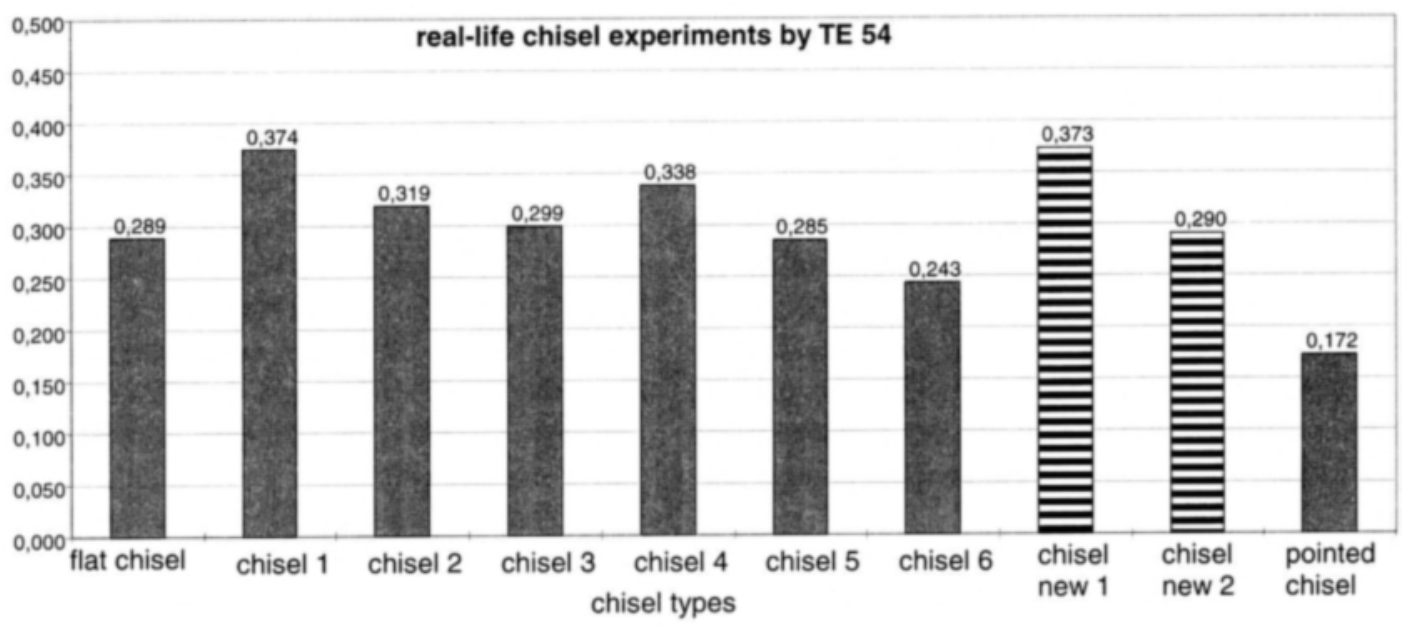

Fig 8. Results of the real-life chisel experiments

lateral impact force, which is supposed to enlarge the crack more efficiently after the crack initialisation, first leads to a prevention of the crack initialisation. This greater strength can be only overcome efficiently by a greater amount of energy for a single impact. Thus the advantage of the diversion of the impact energy for chisels with teeth is partly compensated, because a greater strength is also observed in the area where the crack formation usually occurs. Therefore chisels with lateral teeth are to be seen as unfavourable for combination hammers with a small amount of energy for the single impact.

\section{References}

1. Dahms J. The impact strength of concrete (Die Schlagfestigkeit des Betons). Düsseldorf: Series of the cement industry, Heft 34, 1968. 131 p. (in German).

2. Cronjäger L., Jahn R. Formulation of a technical testing method for designation of vibration loading at the work with rotary hammers (Erarbeitung von technischen Prüfverfahren zur Bestimmung der Schwingungsbelastung beim Arbeiten mit handgeführten Bohrhämmern und Schlagbohrmaschinen). Bremenhaven: Wirtschaftsverlag NW, Series of the Federal Authority for occupational safety, 1985. 148 p. (in German). 
3. Hecker R., Leistner P. Acoustic signal of stone by impact loading with rotary hammers (Signalemission des Gesteins bei der schlagenden Bearbeitung durch Schlag- und Bohrhämmer). Düsseldorf: VDI-Verl., 1995. 114 p. (in German).

4. Duda H. Fracture mechanic behaviour of concrete under monotonic and cyclic tension (Bruchmechanisches Verhalten von Beton unter monotoner und zyklischer Zugbeanspruchung). Berlin: Beuth Deutscher Ausschuß für Stahlbeton, 419, 1991. 60 p. (in German).

5. Hariri K. Fracture mechanical behaviour of young concrete: laser-speckle-interferometry and modelling the crack process zone (Bruchmechanisches Verhalten des jungen Betons: Laser-Speckle-Interferometrie und Modellierung der Rißprozeßzone). Berlin: Beuth Deutscher Ausschuß für Stahlbeton, 2000. 112 p. (in German).

6. Minnert J. Loading behaviour of edgeless impact prefabricated columns by high-strength concrete (Tragverhalten von stumpf gestoßenen Fertigteilstützen aus hochfestem Beton). Berlin: Beuth Deutscher Ausschuß für Stahlbeton, 499, 2000. 159 p. (in German).

7. Schneider 1. Flow behaviour and morphology influence granulated more brittle materials on high pressure and velocity (Fließverhalten und Morphologieeinfluß granulierter spröder Materialien bei hohen Drücken und Belastungsgeschwindigkeiten). Chemnitz: Techn. Univ., Diss., 2001. 129 p. (in German).

8. DIN VDE 0740 Manual of electric machines (items) (Handgeführte Elektrowerkzeuge (Begriffe)). Köln: Beuth, 1985. 26 p. (in German).
9. Junghanns H., Herzog H. K. The piano fabrication (Der Piano- und Flügelbau). Frankfurt am Main: Bochinsky, 1991. 410 p. (in German).

10. Zhao, G. Development and optimisation of a hydraulic rotary hammers (Entwicklung und Optimierung eines hydraulischen Bohrhammers). Düsseldorf: VDI-Verl., 1997. 108 p. (in German).

11. Böge A. Technical mechanics (Technische Mechanik). Braunschweig: Viewegs, 2001. 412 p. (in German).

12. Ebeling K., Knopp W. Standards of concrete production: new standard generation (Beton-Herstellung nach Norm: die neue Normengeneration). Düsseldorf: 2002, 14. ed. Verl. Bau und Technik. 64 p. (in German).

13. Römpp H. The chemical and molecular biology encyclopaedia (Lexikon Chemie und Molekularbiologie). Stuttgart: Thieme, 2000. 725 p. (in German).

14. Curbach $M$. Strength enhancement of concrete at high loading velocity (Festigkeitssteigerung von Beton bei hohen Belastungsgeschwindigkeiten). Karlsruhe: Institut for massive structure and building material technologie, Univ. Karlsruhe, 1987. 154 p. (in German).

15. Peters B. Continuum mechanics analysis of communicability of physical crack initiation (Kontinuumsmechanische Untersuchung zur Übertragbarkeit der physikalischen Rißinitiierungs-werte). Düsseldorf: VDI-Verl., 1997. 108 p. (in German). 